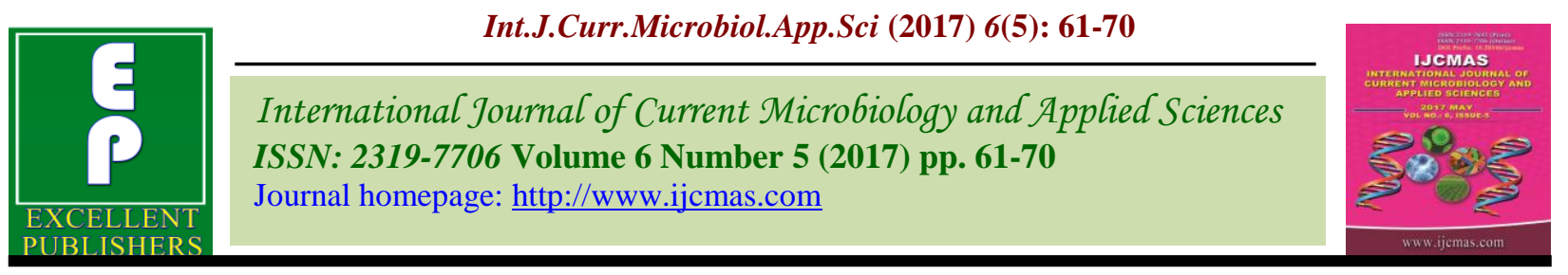

Original Research Article

https://doi.org/10.20546/ijcmas.2017.605.008

\title{
Survey of Magnaporthe grisea Isolates around Andhra Pradesh and Telangana States, India
}

\author{
Ramesh Babu Surapu*, P. Srinivas, J. Aruna, S. Vijay, \\ P.Ch. Durga Rani, Narayan Reddy and M.S. Prasad \\ ${ }^{1}$ Professor Jayashankar Telangana State Agricultural University, Hyderabad, \\ Telangana (500 030), India \\ ${ }^{2}$ Indian Institute of Rice Research, Hyderabad, Telangana (500 030), India \\ *Corresponding author
}

\section{A B S T R A C T}

\section{Keywords}

Rice blast, Survey,

Cultural and

Morphological

characters.

Article Info

Accepted:

04 April 2017

Available Online:

10 May 2017
Rice blast caused by Magnaporthe grisea is one of the most destructive diseases of rice causing significant grain yield losses. Keeping in view the importance of disease, studies were conducted on cultural and morphological characters at Indian Institute of Rice Research (IIRR), Hyderabad, Telangana. Survey was carried out to identify and characterize the fungal pathogen associated with rice blast disease in different crop growing regions of Andhra Pradesh and Telangana states. A total of 40 blast disease specimens were collected from different locations of Andhra Pradesh and Telangana and disease severity was recorded. Later the associated pathogen was isolated and identified. In pathogenic studies, considerable variation was found among the isolates. Isolates which showed excellent sporulation index-4 (RBNL 12, RBMU 37, RBPB 38, RBDR 1, RBKM 8 and RBMT 11) has also recorded high PDI (78.13-80) under artificial inoculation on HR-12. The sporulation index-1 of the isolates RBRG 20, RBTP 13 and RBND 24 was poor but they showed high PDI (70.01-80.23) on HR-12 under artificial inoculation.

\section{Introduction}

Rice [Oryza sativa] is a major staple food and a mainstay for the rural population and their food security. It is widely cultivated in India, China, Indonesia, Bangladesh, Vietnam, Thailand, Myanmar, Japan, Philippines and Brazil. China is the leading rice producer followed by India, Indonesia and Bangladesh in 2013-14 (Commodity profile for riceJanuary 2015). India was the largest exporter of rice in 2013-14 followed by Thailand, Vietnam and USA. The regions cultivating this crop in India are distinguished as the Western coastal strip, the Eastern coastal strip, covering all the primary deltas, Assam plains and surrounding low hills, foothills and Terai region along the Himalayas and states like West Bengal, Bihar, Eastern Uttar Pradesh, Eastern Madhya Pradesh, Northern Andhra Pradesh and Orissa. India, being a land of eternal growing season, and the deltas of Kaveri river, Krishna river, Godavari river and Mahanadi river with a thick set-up of canal irrigation, permits farmers to raise two, and in some pockets, even three crops a year (Department of Agriculture, 2015). 
Rice blast caused by Magnaporthe grisea (Hebert, 1971) Barr (Anamorph: Pyricularia grisea (Cooke) Sacc.) a filamentous ascomycetes fungus infecting more than 50 hosts. Rice blast was first recorded in China (1637) later from Japan (1704). In India, the disease gained importance when a devastating epidemic occurred in Thanjavur (Tanjore) delta of Tamilnadu during 1919. In Andhra Pradesh, it was first identified in Chittoor district subsequently at Nizamabad in Telangana (Nagarajan, 1988). The disease is recorded from almost all the rice growing regions of India. However, the intensity of the disease varies in different regions in different years. All aboveground parts viz., the leaf blade, collar region, neck of the panicle and nodes on the culm are attacked by the fungus. The pathogen is adaptable to adverse environmental conditions of widely fluctuating temperatures and relative humidity. It appears in irrigated low land or rain fed upland rice as well as in submerged or deep water rice. Rice was important crop in both Andhra Pradesh and Telangana states and losses due disease was also more. Keeping this in view we are conducting survey in both the states to identify the severity of disease.

\section{Materials and Methods}

This experiment was conducted during 20132015.

\section{Isolation of mono-conidial isolates of Magnaporthe grisea}

The fungus was isolated by tissue segmentation method (Bonman et al., 1987). Blast infected leaf tissues stored in refrigerator were cut into small bits. These bits were washed in sterilized distilled water twice, surface sterilized in $0.1 \%$ mercuric chloride for 30 seconds, rinsed three times in sterilized water and allowed for sporulation on sterilized glass slides by incubating in a moist chamber at $25^{\circ} \mathrm{C}$ for $48 \mathrm{~h}$. Well sporulated lesions were placed in double distilled water in the test tubes and vortexed for $1 \mathrm{~min}$. About $1 \mathrm{ml}$ of spore suspension was added to sterilized plates and 2\% agar was added. Single spores were located and picked up microscopically and transferred to fresh sterilized Petri plates containing OMA medium. The Petri plates were incubated at $28^{\circ} \mathrm{C}$ for 7 days and the fungus was identified following mycological description

\section{Cultural and morphological variability among $M$. grisea isolates}

Cultural and morphological characters of all monoconidial isolates of $M$. grisea were recorded by growing them on OMA medium for 15 days at $28^{\circ} \mathrm{C}$. Cultural characters include color and radial growth $(\mathrm{mm})$ of the fungal mycelium. Morphological characteristics viz., size of conidia, septa formation and sporulation. Spores of $M$. grisea of different isolates were collectedfrom the culture plate mounted in lactophenol on a clean slide. Spores were measured under high power objective (40x) using precalibrated ocular micrometer. The average size of spore was then determined and shape of the spores were recorded. Microphotographs were taken to show the typical spore morphology of the pathogen.

\section{Sporulation}

Sporulation capacity of each isolate was assessed by microscopic observations. For this purpose, spore suspension from each isolate was prepared by harvesting spores into $20 \mathrm{ml}$ of sterile distilled water from a 15-dayold culture plate using camel hair brush. A loopful of spore suspension was then placed on a clean slide and a cover slip was placed on it. The rate of sporulation was recorded in five different microscopic fields. 


\begin{tabular}{|c|c|c|}
\hline Sporulation & $\begin{array}{c}\text { Number of } \\
\text { spores/microscopic field }\end{array}$ & Index \\
\hline Excellent & $>30$ & 4 \\
\hline Good & $20-30$ & 3 \\
\hline Fair & $10-20$ & 2 \\
\hline Poor & $<10$ & 1 \\
\hline
\end{tabular}

\section{Results and Discussion}

Collection, isolation and purification of $M$. grisea isolates

A roving survey was carried out in nine districts of Telangana and ten districts of Andhra Pradesh to assess the incidence of rice blast and to collect the blast infected leaf samples for isolation of $M$. grisea isolates during rabi 2013 and kharif 2014. The percentage disease index was more during rabi 2013 (56.43) over kharif 2014 (50.87). Based on microscopic examinationthe pathogen was identified as Magnaporthe grisea (Hebert, 1971) Barr. (Anamorph=Pyricularia grisea Sacc.).

A total of 40 blast disease samples from rice were collected from different locations of Andhra Pradesh and Telangana regions during the rabi 2013 (21 samples) and kharif 2014 (19 samples). The collection sites include hot spots for blast disease in both the regions. These isolates were collected from different locally cultivated rice varieties. The results indicated that disease incidence in different agro climatic regions ranged from $36.66 \%$ on MTU 1010 variety (Palem) Mahabubnagar district to $78.88 \%$ on HR-12 (IIRR) Rangareddy district. The maximum disease incidence was noticed in IIRR $(78.88 \%)$ followed by Medak (71.11\%), Tirupati and Chirala (67.55\%). The PDI of blast among different cultivars and locations was significant. The differences in PDI observed among RBGV 35, RBMU 37, RBPK 40, RBAW 33, RBAV 27, RBNB 16, RBVN 2 and RBNG 7 isolates were non-significant (Table 2).
The results indicate that, the mean blast PDI recorded in Krishna Zone was 55.33, in Godavari Zone 53.13, in North Coastal Zone 46.17, in Southern Zone 55.97, in Scarce Rain fall Zone 61.48, in Northern Telangana Zone 54.80, in Central Telangana Zone 52.39 and in Southern Telangana Zone 51.81 (Table 2).

Among the cultivars highest PDI of 78.88 was recorded on HR-12 variety in RBDR 1 and lowest PDI of 36.66 was recorded on MTU1010 in RBPM 9. These results indicate variation in PDI which was influenced by the geographical area under cultivation. In BPT5204, the mean PDI of 41.56 was lowest in North Coastal Zone and highest PDI of 60.03 was in Southern Telangana Zone indicating variation in percent blast disease index was influenced by geographical area under cultivation and the race of $M$. grisea prevailing in these areas.

In MTU-1010, the PDI in Southern Telangana Zone was 36.66, in Central Telangana Zone it was 50. This shows a variation in PDI influenced by geographical area under cultivation. On MTU-1001, the mean PDI in Southern Telangana Zone was 45.1 while in Central Telangana Zone 55.51, in Northern Telangana Zone 57.55, in Godavari Zone 53.13, in Krishna Zone 56.49 and in Scarce Rainfall Zone 61.48.

The variation in PDI may be influenced by geographical area under cultivation or the race prevailing in the region or interaction of the variety and the weather condition in these areas.

In WGL-44645, the mean PDI was 53.89 in Northern Telangana Zone whereas PDI in Central Telangana Zone was 45.44. The isolates (RBMT 11, RBNL 12, RBMU 37, RBPB 38, RBKM 8 and RBDR 1) which produced excellent sporulation (Index-4) recorded variation in PDI on different rice 
varieties. In different agro climatic zones the PDI varied from 40 (RBPB 38) to 78.88 (RBDR 1) under artificially inoculated conditions and on susceptible HR-12 variety these isolates showed high disease incidence.

\section{Cultural diversity among the $M$. grisea isolates}

Diversity in cultural characteristics of $M$. grisea isolates was studied on oat meal agar medium. Variation was observed in colony characteristics viz., growth, color of the vegetative growth and surface appearance among the isolates of $M$. grisea and results are presented in table 2 .

Colony growth of $M$. grisea isolates on oatmeal agar medium revealed significant differences among the isolates from different locations. The colony diameter ranged between $70 \mathrm{~mm}$ (RBDR1) to $90 \mathrm{~mm}$ (RBWG 19 and RBMD 34). Significant difference was observed in the radial growths of RBDR 1, RBBP2, RBPI 3 and RBMN 10 isolates while the differences among the other isolates were non-significant (Table 2).

The variation among the radial growth may be due to several reasons like autolysis of the mycelium and exhaustion of nutrients in the medium. Lilly and Barnett (1951) opined that the growth in fungi follows a definite pattern and they observed the onset of autolysis after the maximum growth during which cellular enzymes digest the various cell constituents.

Diversity in cultural characters such as color of vegetative growth and texture, were noticed among the isolates, but there was no clear-cut grouping between isolates from different cultivars. The results of the present study grouped 40 isolates into seven categories. First group had greyish white mycelium and smooth surface appearance. This group includes RBGT 4 and RBTN 25. Second group had 28 isolates with greyish white color mycelium and rough surface appearance. Third group had two isolates RBDR 1 and RBNB 16 which showed grey color mycelium and smooth surface appearance. Fourth group had grey color mycelium with rough surface appearance (RBSP 18). Fifth group had greyish green color mycelium and smooth surface (RBPM 9). Sixth group had greyish brown color mycelium and rough surface (RBWG 19). Seventh group had greyish black colony with rough texture (RBTP 13, RBAV 27, RBPD 36, RBMU 37 and RBPB 38) (Table 2).

Isolates collected from cultivar BPT 5204 in Krishna Zone showed grayish white colour appearance and rough surface on oat meal agar medium and showed good sporulation (Index-3). RBRG 20 isolate collected from BPT 5204 in North Coastal Zone showed greyish white color mycelium and rough surface with poor (Index-1) sporulation while RBSP 18isolate collected from BPT 5204 in North Coastal Zone showed grey color mycelium and rough surface with good (Index-3) sporulation. RBAC 30 isolate collected from BPT 5204 in South Telangana Zone also showed greyish white color mycelium and rough surface with good (Index-3) sporulation. RBPM 9isolate collected from MTU-1010 in South Telangana Zone showed greyish green color mycelium and smooth surface with fair (Index-2) sporulation. RBMD 34 isolate collected from MTU-1010 in Central Telangana Zone showed greyish white color mycelium and rough surface with good (Index-3) sporulation. Isolates (RBMU 37, RBPB 38 and RBTP 13) collected from NLR145 in Southern Zone showed greyish black color mycelium and rough surface with excellent (Index-4) sporulation except RBTP 13, recorded poor (Index-1) sporulation. RBNL 12 isolate collected from NLR-145 in Southern Zone showed greyish white color mycelium and rough surface with excellent (Index-4) sporulation. 
Table.1 List of P. oryzae isolates collected from Andhra Pradesh and Telangana, their designation codes

\begin{tabular}{|c|c|c|c|c|}
\hline S. No & State & District & Isolate & Designation \\
\hline 1 & Telangana & Rangareddy & IIRR & RBDR 1 \\
\hline 2 & Andhra Pradesh & Guntur & Bapatla & RBBP 2 \\
\hline 3 & Andhra Pradesh & Guntur & Piduguralla & RBPI 3 \\
\hline 4 & Andhra Pradesh & Guntur & Guntur & RBGT 4 \\
\hline 5 & Andhra Pradesh & Guntur & Rentachintala & RBRC 5 \\
\hline 6 & Andhra Pradesh & Krishna & Vijayawada & RBVI 6 \\
\hline 7 & Telangana & Nalgonda & Nalgonda & RBNG 7 \\
\hline 8 & Telangana & Khammam & Khammam & RBKM 8 \\
\hline 9 & Telangana & Mahbhubnagar & Palem & RBPM 9 \\
\hline 10 & Andhra Pradesh & Kurnool & Mahanandi & RBMN 10 \\
\hline 11 & Andhra Pradesh & West Godavari & Marteru & RBMT 11 \\
\hline 12 & Andhra Pradesh & Nellore & Nellore & RBNL 12 \\
\hline 13 & Andhra Pradesh & Chittor & Tirupathi & RBTP 13 \\
\hline 14 & Telangana & Medak & Patancheru & RBMK 14 \\
\hline 15 & Telangana & Karimnagar & Jagityal & RBJG 15 \\
\hline 16 & Telangana & Nijamabad & Nizamabad & RBNB 16 \\
\hline 17 & Telangana & Adilabad & Adilabad & RBAB 17 \\
\hline 18 & Andhra Pradesh & Srikakulam & S.M Puram & RBSP 18 \\
\hline 19 & Telangana & Warangal & Warangal & RBWG 19 \\
\hline 20 & Andhra Pradesh & Srikakulam & Ragolu & RBRG 20 \\
\hline 21 & Andhra Pradesh & Vijayanagaram & Vizianagaram & RBVN 21 \\
\hline 22 & Andhra Pradesh & West Godavari & Veeranasaram & RBVR 22 \\
\hline 23 & Telangana & Adilabad & Basara & RBBS 23 \\
\hline 24 & Andhra Pradesh & Kurnool & Nadyal & RBND 24 \\
\hline 25 & Andhra Pradesh & East Godavari & Tuni & RBTN 25 \\
\hline 26 & Andhra Pradesh & Prakasam & Chirala & RBCH 26 \\
\hline 27 & Andhra Pradesh & Guntur & Adivi & RBAV 27 \\
\hline 28 & Andhra Pradesh & Guntur & Amaravati & RBAM 28 \\
\hline 29 & Andhra Pradesh & Guntur & Karempudi & RBKP 29 \\
\hline 30 & Telangana & Mahabhubnagar & Atchempet & RBAC 30 \\
\hline 31 & Andhra Pradesh & Guntur & Mangalagiri & RBMG 31 \\
\hline 32 & Telangana & Nalgonda & Aleru & RBAL 32 \\
\hline 33 & Telangana & Khammam & Aswaraopet & RBAW 33 \\
\hline 34 & Telangana & Khammam & Madhira & RBMD 34 \\
\hline 35 & Andhra Pradesh & Krishna & Gopavaram & RBGV 35 \\
\hline 36 & Andhra Pradesh & West Godavari & Poduru & RBPD 36 \\
\hline 37 & Andhra Pradesh & Nellore & Muttukuru & RBMU 37 \\
\hline 38 & Andhra Pradesh & Nellore & Penubarti & RBPB 38 \\
\hline 39 & Telangana & Ranga Reddy & Tandur & RBTD 39 \\
\hline 40 & Andhra Pradesh & West Godavari & Palakollu & RBPK 40 \\
\hline
\end{tabular}


Table.2 List of P. oryzae isolates collected from Andhra Pradesh and Telangana, their designation codes

\begin{tabular}{|c|c|c|c|c|c|c|}
\hline Cultivar & Isolate & Agro climatic Zone & Colour & Texture & Sporulation & PDI \\
\hline \multirow[t]{14}{*}{ BPT-5204 } & RBBP2 & K.Z & Greyish white & Rough & 3 & 50.00 \\
\hline & RBPI 3 & K.Z & Greyish white & Rough & 3 & 47.65 \\
\hline & RBGT 4 & K.Z & Greyish white & Smooth & 2 & 59.74 \\
\hline & RBRC 5 & K.Z & Greyish white & Rough & 3 & 53.28 \\
\hline & RBVI 6 & K.Z & Greyish white & Rough & 3 & 58.55 \\
\hline & RBCH 26 & K.Z & Greyish white & Rough & 3 & 67.55 \\
\hline & RBAV 27 & K.Z & Greyish black & Rough & 3 & 55.40 \\
\hline & RBAM 28 & K.Z & Greyish white & Rough & 3 & 53.52 \\
\hline & RBKP 29 & K.Z & Greyish white & Rough & 3 & 61.07 \\
\hline & RBMG 31 & K.Z & Greyish white & Rough & 3 & 45.41 \\
\hline & RBSP 18 & N.C.Z & Grey & Rough & 3 & 43.25 \\
\hline & RBRG 20 & N.C.Z & Greyish white & Rough & 1 & 39.87 \\
\hline & RBAC 30 & S.T.Z & Greyish white & Rough & 3 & 60.03 \\
\hline & Mean & & & & & 53.48 \\
\hline \multirow[t]{3}{*}{ MTU-1010 } & RBPM 9 & S.T.Z & Greyish green & Smooth & 2 & 36.66 \\
\hline & RBMD 34 & C.T.Z & Greyish white & Rough & 3 & 50.00 \\
\hline & Mean & & & & & 43.33 \\
\hline \multirow[t]{5}{*}{ NLR-145 } & RBNL 12 & S.Z & Greyish white & Rough & 4 & 59.87 \\
\hline & RBTP 13 & S.Z & Greyish black & Rough & 1 & 67.55 \\
\hline & RBMU 37 & S.Z & Greyish black & Rough & 4 & 56.49 \\
\hline & RBPB 38 & S.Z & Greyish black & Rough & 4 & 40.00 \\
\hline & Mean & & & & & 55.97 \\
\hline HR-12 & RBDR 1 & S.T.Z & Grey & Smooth & 4 & 78.88 \\
\hline RGL-2624 & RBVN 21 & N.C.Z & Greyish white & Rough & 2 & 55.41 \\
\hline \multirow[t]{16}{*}{ MTU-1001 } & RBNG 7 & S.T.Z & Greyish white & Rough & 3 & 55.52 \\
\hline & RBTD 39 & S.T.Z & Greyish white & Rough & 3 & 37.60 \\
\hline & RBAL 32 & S.T.Z & Greyish white & Rough & 3 & 42.18 \\
\hline & RBMK 14 & C.T.Z & Greyish white & Rough & 3 & 71.11 \\
\hline & RBAW 33 & C.T.Z & Greyish white & Rough & 2 & 55.41 \\
\hline & RBKM 8 & C.T.Z & Greyish white & Rough & 4 & 40.01 \\
\hline & RBAB 17 & N.T.Z & Greyish white & Rough & 2 & 57.55 \\
\hline & RBVR 22 & G.Z & Greyish white & Rough & 3 & 47.55 \\
\hline & RBMT 11 & G.Z & Greyish white & Rough & 4 & 56.49 \\
\hline & RBTN 25 & G.Z & Greyish white & Smooth & 2 & 46.49 \\
\hline & RBPD 36 & G.Z & Greyish black & Rough & 3 & 58.65 \\
\hline & RBPK 40 & G.Z & Greyish white & Rough & 3 & 56.49 \\
\hline & RBGV 35 & K.Z & Greyish white & Rough & 3 & 56.49 \\
\hline & RBND 24 & S.R.Z & Greyish white & Rough & 1 & 59.70 \\
\hline & RBMN 10 & S.R.Z & Greyish white & Rough & 2 & 63.26 \\
\hline & Mean & & & & & 49.86 \\
\hline \multirow[t]{5}{*}{ WGL-44645 } & RBJG 15 & N.T.Z & Greyish white & Rough & 2 & 48.64 \\
\hline & RBNB 16 & N.T.Z & Grey & Smooth & 2 & 56.52 \\
\hline & RBBS 23 & N.T.Z & Greyish white & Rough & 3 & 56.52 \\
\hline & RBWG 19 & C.T.Z & Greyish brown & Rough & 3 & 45.44 \\
\hline & Mean & & & & & 51.78 \\
\hline
\end{tabular}

"K.Z (Krishna Zone), G.Z (Godavari Zone), N.C.Z (North Coastal Zone), S.Z (Sothern Zone), S.R.Z (Scarce Rainfall Zone), N.T.Z (Northern Telangana Zone), C.T.Z (Central Telangana Zone), S.T.Z (Southern Telangana Zone) 


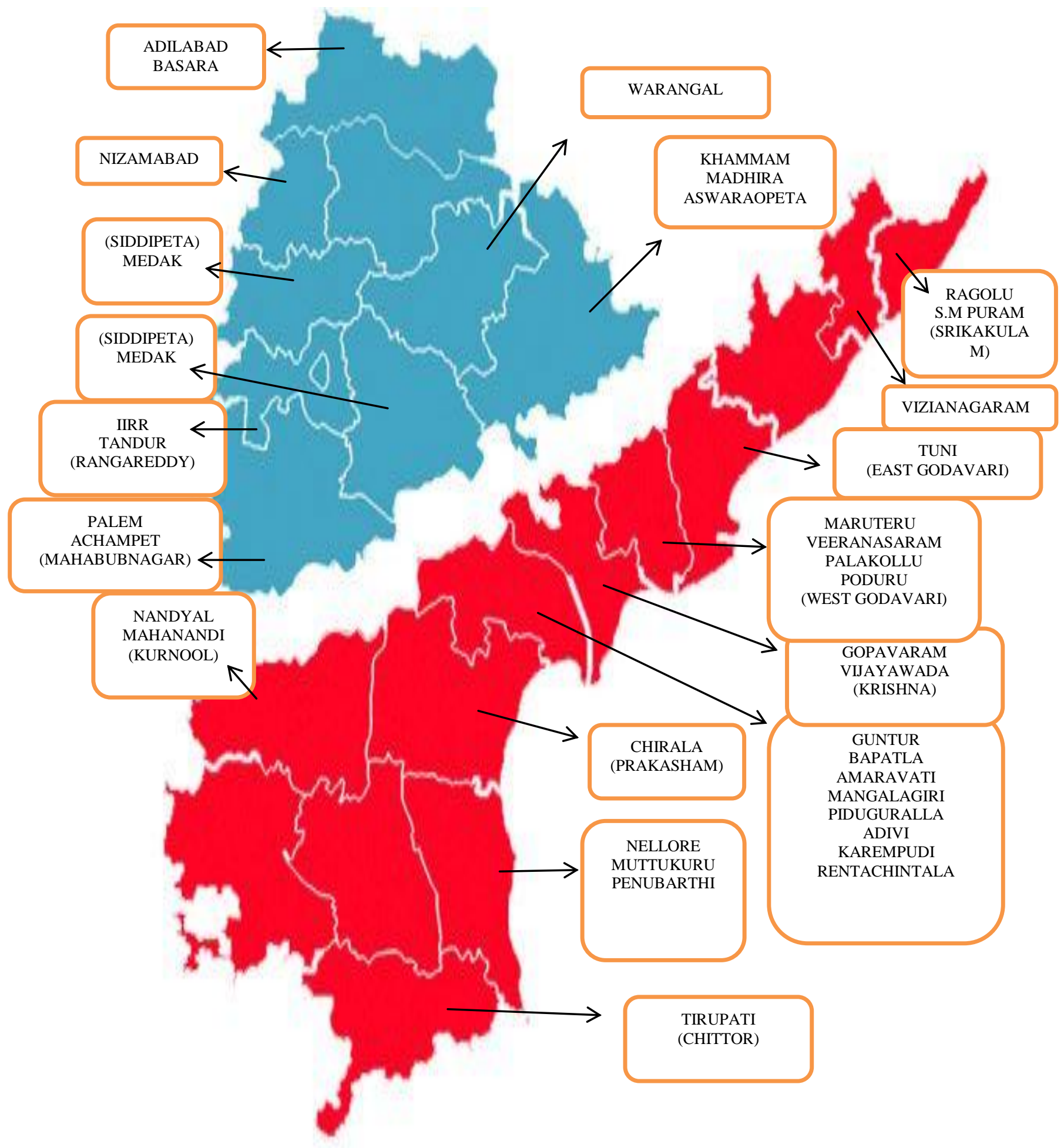


Figure.2 Variation in cultural morphology of $M$. grisea isolates on oat meal agar medium

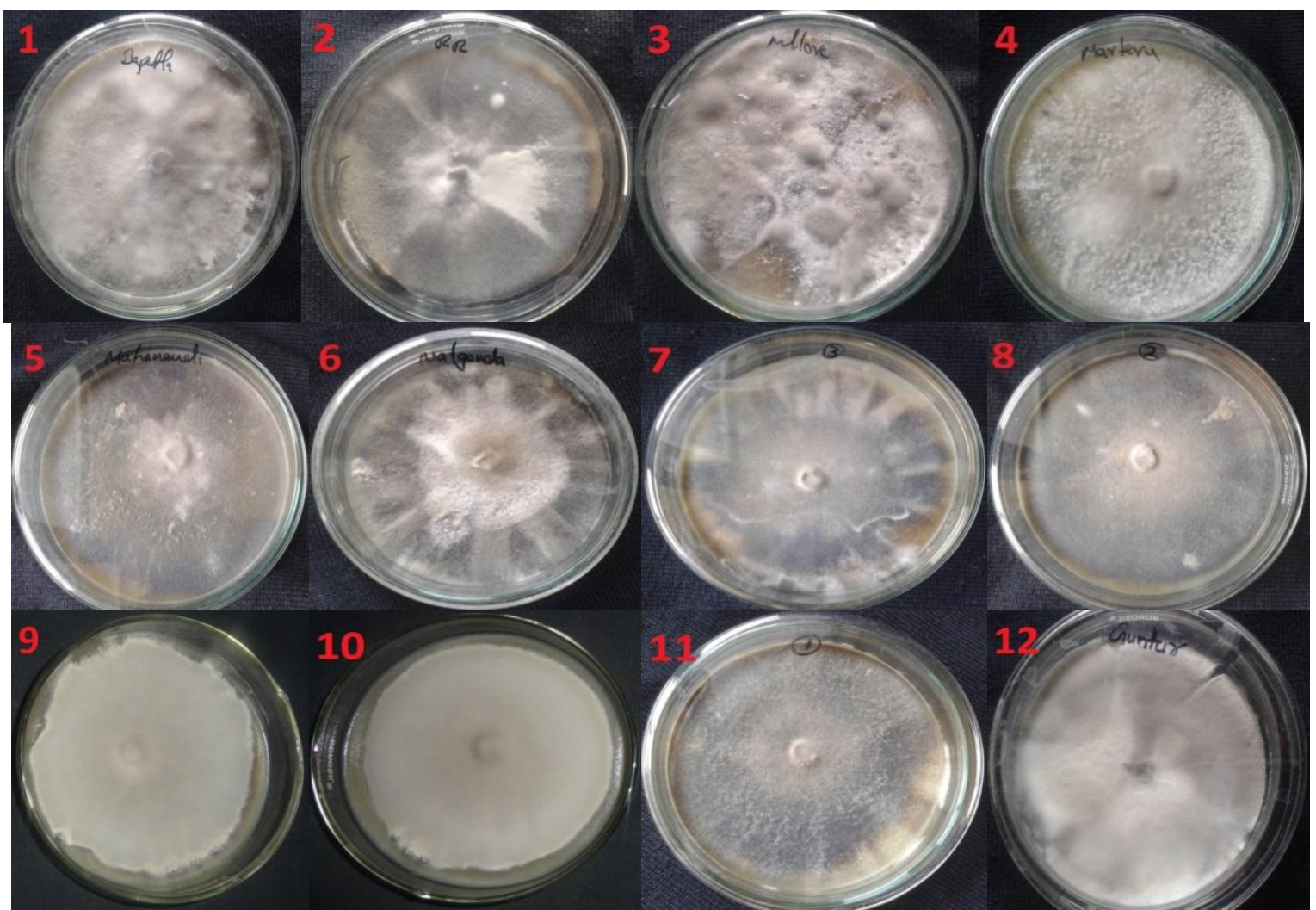

1. Bapatla, 2. Piduguralla, 3. Nellore, 4. Maruteru, 5. Mahanandi, 6. Nalgonda, 7. Vijayawada,

8. Palem, 9. Nizamabad, 10. IIRR, 11. Medak, 12. Guntur

RBDR 1isolate collected from HR-12 in South Telangana Zone showed grey color mycelium and smooth surface with excellent (Index-4) sporulation. RBVN 21 isolate collected from RGL-2624 in North Coastal Zone showed greyish white color mycelium and rough surface with fair (Index-2) sporulation. Isolates collected from MTU1001 in all zones showed greyish white mycelium with rough surface except RBTN 25, which was recorded smooth texture. Sporulation for all these isolates ranged from index 1-4. RBJG 15 and RBBS 23 isolates collected from WGL-44645 in North Telangana Zone showed greyish white mycelium and rough surface with sporulation index 2 and 3 respectively. RBNB 16 isolate collected from WGL-44645 in North Telangana Zone showed grey color mycelium and smooth surface with fair (Index 2) sporulation. RBWG 19 isolate collected from WGL-44645 in Central Telangana Zone showed greyish brown color mycelium and rough surface with good (Index 3) sporulation (Table 2).

These results are in agreement with Srivastava et al., (2014) who reported existence of variability among the isolates of $M$. grisea with respect to conidial size and was well documented by many workers.

Morphological diversity among the $M$. grisea isolates

Isolates significantly varied in spore morphology. The fungus produced a single bottle-shaped conidiogenous cell bearing 3-5 conidia arranged in a cluster at the active apical tip or they were formed successively 
and sympodially in a characteristic pattern, i.e. the active apical tip moves to the side to produce next conidium, resulting 3-5 conidia borne sympodially on mature conidiophore. The successive and sympodial bearing of spores was commonly observed with the isolates. Mature conidia of $M$. grisea were pyriform, almost hyaline to pale olive, 2septate, 3-celled, the middle cell being wider and darker, and exhibit a basal appendage at the point of attachment to the conidiophore. End cells and middle cells germinate giving out germ tubes.

The shape of the conidia was pyriform. The size of the conidia varied among the isolates between $25.5 \mu \mathrm{m}$ (RBWG 19, RBBS 23, RBMD 34 and RBGV 35) to $38.5 \mu \mathrm{m}$ (RBNG 7). The length of the conidia ranged from 8 (RBPI 3) to $11 \mu \mathrm{m}$ (RBNG 7) and width were ranged from 3 (RBMT 11, RBNL 12 etc.) to 4 $\mu \mathrm{m}$ (RBAW 33 and RBPB 38).

The degree of sporulation was compared with the growth patterns of the pathogen. It was observed that isolates that were having rough surface showed more sporulation compared with smooth surface isolates with exception of IIRR isolate. IIRR isolate having smooth surface but produced excellent (Index-4) sporulation. The other isolates having smooth surface (RBGT 4, RBPM 9, RBNB 16 and RBTN 25) produced fair sporulation (Index2).

The isolates which showed excellent sporulation of index-4 were having greyish white mycelium (RBNL 12 and RBKM 8), greyish black mycelium (RBMU 37 and RBPB 38) and grey colour mycelium (RBDR 1). The isolates which showed poor sporulation of index-1 were having greyish white mycelium (RBND 24 and RBRG 20) and greyish black mycelium (RBTP 13). Vegetative growth of most of the isolates showed greyish white appearance while
RBDR 1, RBNB 16 and RBSP 18 isolate showed the grey appearance. RBPM 9 showed greyish green mycelium and RBWG 19 showed greyish brown appearance. RBPD 36, RBMU 37, RBPB 38, RBAV 27 and RBTP 13 showed greyish black appearance (Table 2 and Figure 2).

With regard to sporulation (Index 1-4), excellent sporulation (Index 4) was noticed in RBDR 1, RBKM 8, RBMT 11, RBNL 12, RBMU 37 and RBPB 38 whereas in RBTP 13, RBRG 20, and RBND 24 isolates it was poor sporulation. Variation in sporulation capacity was also noticed among the isolates.

The size and shape of spores are important criteria for classification and identification of Pyricularia species. The results of the present study indicate morphological variation in terms of conidial size and sporulation and also noticed that isolates which had poor sporulation also recorded high PDI.

Shahijahandar et al., (2010) recorded prevalence and distribution of blast in Kupwara district of Jammu and Kashmir and reported $25 \%$ disease incidence and $15 \%$ severity.

In all the districts of Southern Telangana Zone of Andhra Pradesh (Jagadeeshwar et al., 2014) reported 30-35\% incidence of neck blast if the crop was in flowering stage coinciding with North-east monsoon.

It can be concluded that these results indicated that blast isolates were distributed throughout Telangana and Andhra Pradesh. It was also concluded that the disease severity was more in both states.

\section{Acknowledgments}

I thank P. Narayan Reddy and M. Srinivas Prasad for giving opportunity to work in Lab. 


\section{References}

Bonman, J.M., Vergel de Dios, T.I., Bandong, J.M., Lee, E.J. 1987. Pathogenic variability of monoconidial isolates of Pyricularia oryzae in Korea and in the Philippines. Plant Dis., 71: 127-130.

Jagadeeshwar, R., Rama Gopala Varma, N., Raghu Rami Reddy, P., Surender, R.C., Vanisree, S., Gopal Reddy, B., Dayakar, S. 2014. Screening of new fungicides against location specific diseases of rice occurring in Southern Telangana zone of Andhra Pradesh. The J. Res., ANGRAU, 42(1): 18-21.

Hebert, T.T. 1971. The perfect stage of Pyricularia grisea. Phytopathol., 61: 83-87.

Lilly, V.G., Barnett, H.L. 1951. Physiology of the Fungi. McGraw Hill Book Co. Inc. New York, 441.
Nagarajan, S. 1988. Epidemiology and loss of rice, wheat and pearl millet crops due to diseases. In: International Symposium on crop Losses and Diseases Outbreaks in Tropics and Control measures. Tropical Agriculture Research Centre, Japan. 209.

Shahijahandar, M., Hussain, S., Nabi, G.H., Masood, M. 2010. Prevalence and distribution of blast disease (Magnaporthe grisea) on different components of rice plants in paddy growing areas of the Kashmir Valley. Int. J. Pharm. Biosci., 1-4.

Srivastava, D., Shamim, M.D., Kumar, D., Pandey, P., Khan, N.A. and Singh, S.N. 2014. Morphological and molecular characterization of Pyricularia oryzae causing blast disease in rice (Oryzae sativa) from North India. Int. J. Scientific and Res. Publications, 4(7): 2250-3153.

\section{How to cite this article:}

Ramesh Babu Surapu, P. Srinivas, J. Aruna, S. Vijay, P.Ch. Durga Rani, Narayan Reddy and Prasad, M.S. 2017. Survey of Magnaporthe grisea Isolates around Andhra Pradesh and Telangana States, India. Int.J.Curr.Microbiol.App.Sci. 6(5): 61-70. doi: http://dx.doi.org/10.20546/ijcmas.2017.605.008 